\title{
СИНТЕЗ ПОЛУАВТОМАТИЧЕСКОЙ СИСТЕМЫ УПРАВЛЕНИЯ ПОЛОЖЕНИЕМ ЦЕНТРА МАСС САМОЛЕТА В БОКОВОМ ДВИЖЕНИИ ДЛЯ ИМИТАТОРА БЛОКА КСУ ТРЕНАЖЕРНОГО УСТРОЙСТВА ИМИТАЦИИ ПОЛЕТА
}

\section{SYNTHESIS OF A SEMI-AUTOMATIC CONTROL SYSTEM FOR THE POSITION OF THE CENTER OF MASS OF AN AIRCRAFT IN LATERAL MOTION FOR A SIMULATOR OF A BLOCK OF AN INTEGRATED CONTROL SYSTEM OF A FLIGHT SIMULATION TRAINING DEVICE}

S. Mitrofanov S. Rybnikov

Summary. The principle of constructing a semi-automatic control system for the position of the center of mass of an aircraft in lateral movement for a simulator of a block of an integrated control system of a simulator for simulating a flight of a promising medium-range passenger aircraft is briefly described. The characteristics of the pilot as a link of the control system with coefficients for various variants of the frequency of the driving function are described. In the course of the study, the coefficients of the control laws for various flight modes of the aircraft in lateral motion were obtained. Transient graphs demonstrate the quality of the synthesized system.

Keywords: aviation trainer, lateral movement, semi-automatic control system.

\section{Митрофанов Сергей Юрьевич}

Аспирант, ФГБОУ ВО «Московский авиационный институт (национальный исследовательский университет)» seymitrofanov@mail.ru

Рыбников Сергей Игоревич

Д.т.н., ФГБОУ ВО «Московский авиачионный институт (национальный исследовательский университет)» Rybnikov@mail.ru

Аннотация. Кратко описывается принцип построения полуавтоматической системы управления положением центра масс самолета в боковом движении для имитатора блока комплексной системы управления тренажерного устройства имитации полета перспективного среднемагистрального пассажирского самолета. Описываются характеристики пилота как звена системы управления с коэффициентами для различных вариантов частоты вынуждающей функции. В ходе исследования получены коэффициенты законов управления для различных режимов полета самолета в боковом движении. Графики переходных процессов демонстрируют качество синтезированной системы.

Ключевые слова: авиационный тренажер, боковое движение, полуавтоматическая система управления.

\section{Введение}

$\Pi$ олуавтоматическая система управления предусматривает участие человека в передаче сигналов в замкнутых контурах управления и содержит устройства для формирования законов управления.

Полуавтоматические системы управления применяются в тех случаях, когда участие человека в замкнутой системе в качестве ее звена обеспечивает большую точность и безопасность управления, чем это может обеспечить автоматическая система. В полуавтоматических системах человек и управляемый им объект образуют единую систему «человек-машина». Оптимальное взаимодействие человека и машины достигается в случае, если машина сконструирована

с учетом возможностей человека, а человек хорошо знает динамические возможности объекта управления [1]. На рисунке 1 изображена функциональная схема полуавтоматической системы, включая человека (пилота) и объект управления, в качестве которого выбран самолет с его приборами и регулирующими органами.

\section{1. Характеристики пи^ота как звена системы управления}

Пилот, как динамическое звено, является нелинейной системой. Он обладает способностью приспосабливаться к различным по динамическим характеристикам самолетам. Осуществляя управление самолетом, пилот может работать как инерционное, дифференцирующее, 
Таблица 1

\begin{tabular}{|l|l|l|l|l|l|}
\hline $\begin{array}{l}\text { Частота вынуждающей } \\
\text { функции, Гц }\end{array}$ & $1 / T_{l}$ & $1 / T_{l}$ & $T$ & $a$ & $k$ \\
\hline 0.16 & 0.04 & 1.5 & 0.15 & 0.08 & 100 \\
\hline 0.32 & 0.11 & 4.55 & 0.2 & 0.055 & 40 \\
\hline 0.5 & 0.20 & 11 & 0.25 & 0.067 & 15 \\
\hline
\end{tabular}

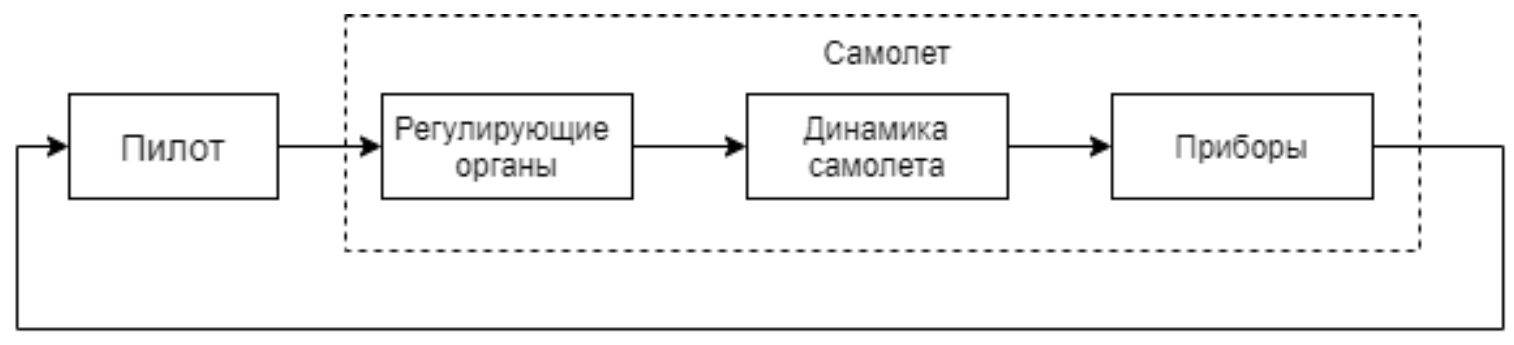

Рис. 1. Функциональная схема связи пилота и самолета

интегрирующее звенья или же выполнять функции блока дискретной выборки данных. Другими словами, оператор как звено является нелинейной динамической системой с переменными параметрами, и со свойствами самоприспособления. Однако такое звено нередко полагают линейным и оценивают передаточные свойства оператора передаточной функцией, справедливой только в частных случаях.

При работе в стационарном контуре управления, подверженном стационарным возмущениям, передаточная функция пилота (оператора) может быть аппроксимирована выражением:

$$
W_{\text {п }}(S)=\frac{k e^{-s T}\left(a T_{1} s+1\right)}{\left(T_{1} s+1\right)\left(T_{2} s+1\right)},
$$

где $T$ - время, характеризующее формирование ответной реакции на входной сигнал; $T_{1}$ и $T_{2}$ - постоянные времени, характеризующие передачу сигнала; $a-$ коэффициент, учитывающий опыт, тренировку, утомление, вид задания и др.

Структурная схема передаточной функции может быть представлена тремя последовательными звеньями. Передаточная функция первого звена имеет вид:

$$
W_{1}(s)=e^{-s T}
$$

Передаточная функция (2) справедлива в том случае, когда пилот при управлении самолетом наблюдает за показаниями только одного прибора, а именно за отклонением одного параметра от заданного значения. При наблюдении за $\mathrm{n}$ параметрами, передаточная функция (2) принимает вид:

$$
W_{1}(s)=e^{-s n T}
$$

Передаточная функция следующего звена представляет собой комбинацию усилительного, апериодического и форсирующего звена:

$$
W_{2}(s)=\frac{k_{1}\left(a T_{1} s+1\right)}{\left(T_{1} s+1\right)}
$$

Постоянная времени $T_{1}$ апериодического звена определяется продолжительностью оценки полученной информации и выработки ответной реакции. Форсирующее звено отражает способность пилота реагировать на скорость изменения контролируемого параметра, а также компенсировать запаздывание в получении информации и выработке ответной реакции.

Передаточная функция следующего звена отражает нервно-мускульные процессы воздействия на органы управления:

$$
W_{3}(s)=\frac{k_{2}}{\left(T_{2} s+1\right)}
$$

Численные значения коэффициентов передаточной функции (1) приведены в таблице 1.

Ответная реакция пилота на непрерывный сигнал является не непрерывной, а дискретной. Это связано с тем, что сигнал или передается в центральную нервную систему или не передается. Тренированный человек способен совершать до двух ответных реакций в секунду при двух раздражениях, это определяет полосу пропусканию частот порядка 0,5 Гц. При этом, чем больше частота воспринимаемого сигнала, тем менее точна ответная реакция оператора на этот сигнал. 
Таблица 2

\begin{tabular}{|l|l|l|l|l|}
$\mathbf{N}$ & $\mathbf{K}_{1}$ & $\mathbf{K}_{2}$ & $\mathbf{K}_{3}$ & $\mathbf{K}_{4}$ \\
\hline 1 & -1.4913 & -2.3278 & 0.6382 & 0.2730 \\
\hline 2 & -1.6823 & -2.7866 & 0.6768 & 0.2804 \\
\hline 3 & -1.9308 & -3.4008 & 0.7453 & 0.2890 \\
\hline 5 & -2.9121 & -5.8623 & 1.1853 & 0.3189 \\
\hline
\end{tabular}

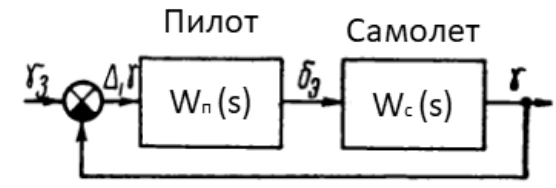

Рис. 2. Структурная схема управления креном

Поскольку пилот не может точно выполнить операции дифференцирования и интегрирования и другие вычисления более высокого порядка, то не следует поручать ему эти операции. Оператор в контуре управления должен выполнять операции, требующие логического мышления, а также функции простого усиления сигналов с частотами, не превышающими 0,5 Гц. Количество информации, предъявляемое оператору для переработки и формирования управляющих сигналов не должно превышать 3-4 бит/с.

\section{2. Синтез структуры полуавтоматического \\ управления положением чентра \\ масс самолета в боковом Авижении}

При аналитическом конструировании системы управления с $n$-мерным вектором фазовых координат $X$, с одним управляющим воздействием u, с квадратной матрицей $A$ коэффициентов внутренних связей и матрицей-столбцом В коэффициентов при управляющем воздействии, на основе математической модели расширенного объекта

$$
d X / d t=A X+B u
$$

определяется алгоритм управления

$$
u=-K X
$$

минимизирующий заданный функционал

$$
J=\int_{0}^{\infty} F\left(x_{1}, x_{2}, \ldots, x_{n}, u\right) d t=\int_{0}^{\infty}\left[\sum_{i=1}^{n} d_{i} x_{i}^{2}(t)+d_{u} u^{2}(t)\right] d t
$$

Для стабилизации центра масс самолета на заданной траектории в боковом движении пилоту необхо- дима информация о боковом отклонении $\Delta z$ самолета от заданной траектории, о первой и второй производных от этого отклонения. Пилот должен воспринимать и анализировать показания трех приборов. Информация об отклонении $\Delta \psi$ текущего курса от заданного используется в качестве информации о скорости отклонения центра масс самолета от заданной траектории, что справедливо при отсутствии бокового ветра: $\dot{z}=V \Delta \psi$.

С учетом отношения $\dot{\psi} \approx \frac{g}{V} \gamma$ очевидна зависимость между второй производной отклонения и креном самолета:

$$
\ddot{z} \approx g \gamma
$$

Внутренний контур синтезируемой системы содержит полуавтоматическую систему управления креном, структурная схема которой, изображена на рисунке 2.

На схеме пилот представлен звеном с передаточной функцией $W_{n}(s)$. На вход звена подается сигнал отклонения текущего крена от его заданного значения: $\Delta \gamma=\gamma_{\text {зад }}-\gamma$.

Приведем результаты нескольких вариантов синтеза и математического моделирования полуавтоматической системы управления углом крена $ү$. В процессе синтеза получены значения коэффициентов закона управления $\mathrm{K}_{1}-\mathrm{K}_{4}$, указанные в таблице 2. Численные значения для передаточной функции пилота приведены в таблице 1 для частоты Вынуждающей функции 0.5 Гц.

Рассматривается отработка заданного значения угла крена $\gamma=30^{\circ}$ без ограничения отклонения элеронов и с ограничением отклонением элеронов $\pm 15^{\circ}$. 


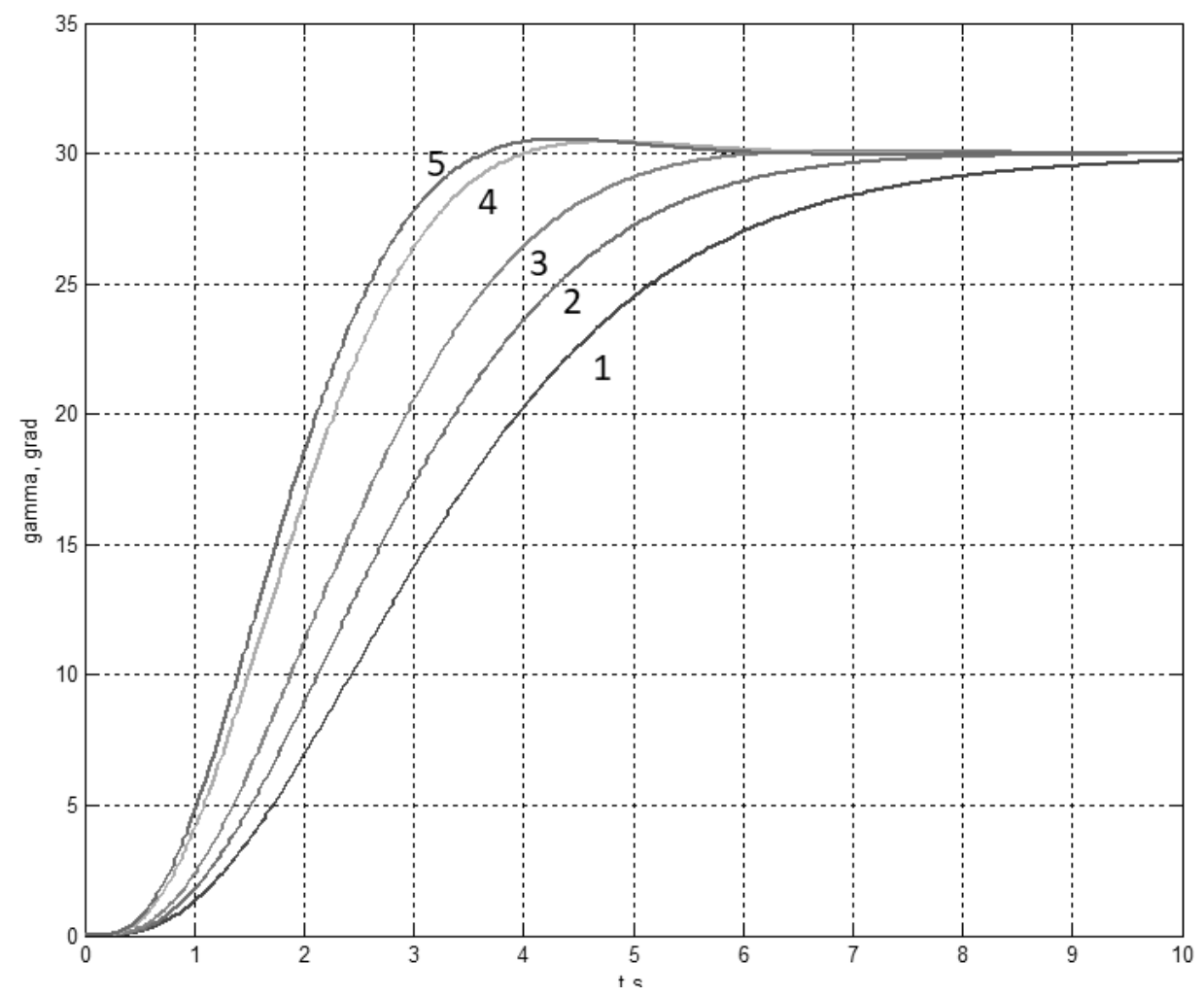

Рис. 3. Переходные процессы по углу крена при различных параметрах $\mathrm{K}_{1}-\mathrm{K}_{4}$

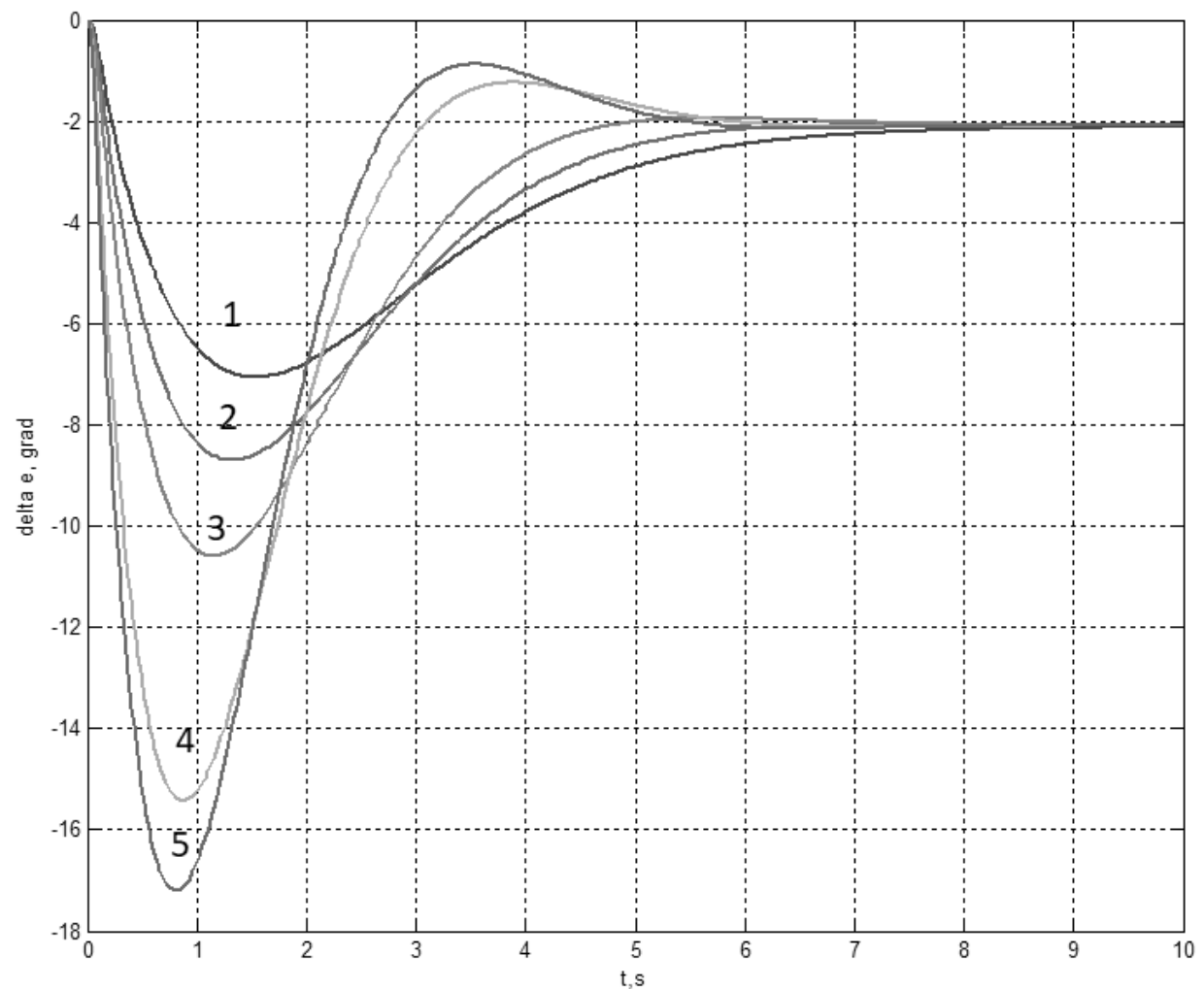

Рис. 4. Переходные процессы по отклонению элеронов при различных параметрах $\mathrm{K}_{I}-\mathrm{K}_{4}$ 


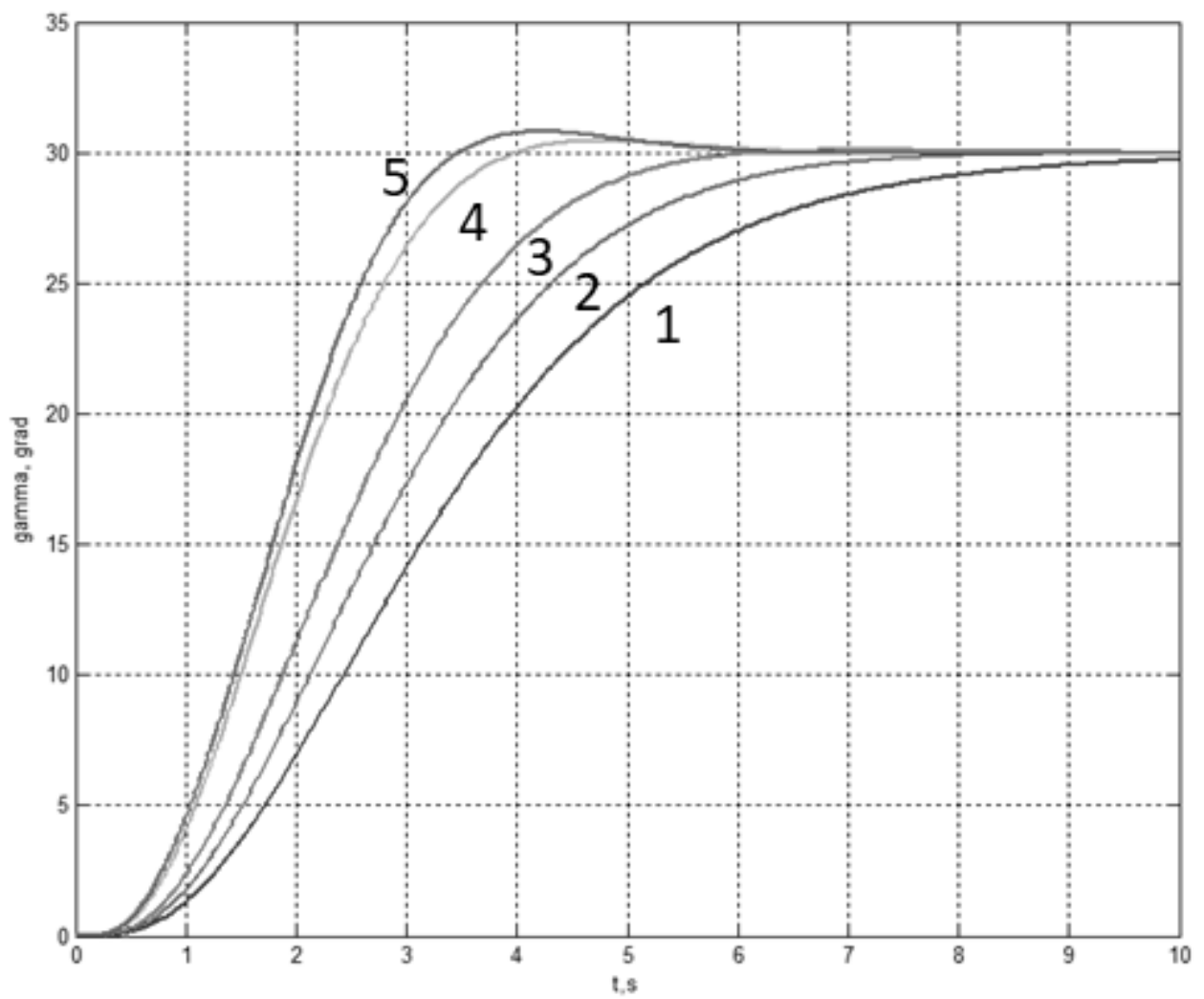

Рис. 5. Переходные процессы по углу крена при различных параметрах $\mathrm{K}_{I}-\mathrm{K}_{4}$

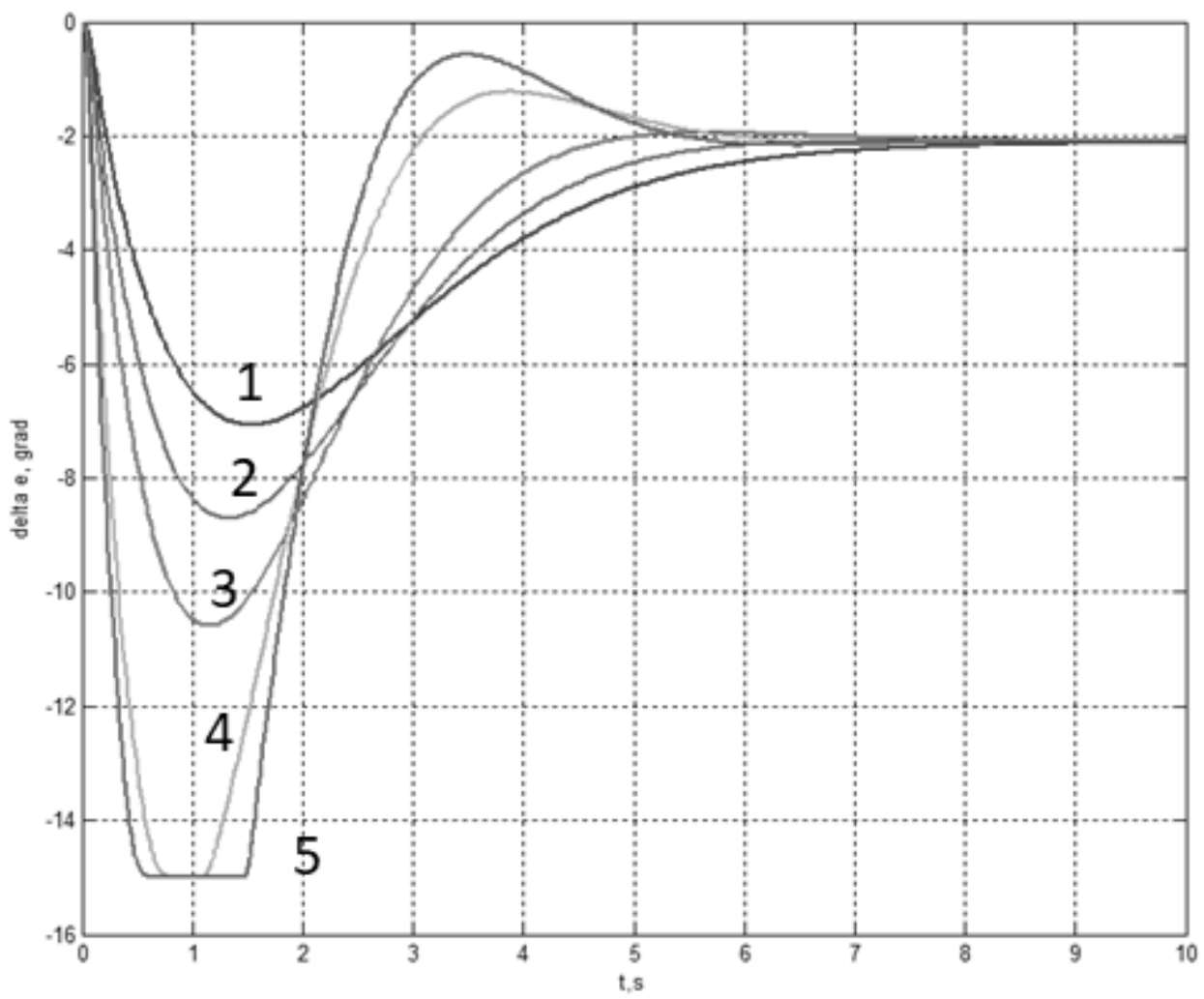

Рис. 6. Переходные процессы по отклонению элеронов при различных параметрах $\mathrm{K}_{l}-\mathrm{K}_{4}$ 
Таблица 3

\begin{tabular}{|l|l|l|l|l|l|}
\hline Варианты & $\mathbf{\omega}, \mathbf{1 / c}$ & $\mathbf{K}(\mathbf{1})$ & $\mathbf{K}(\mathbf{2})$ & $\mathbf{K}(\mathbf{3})$ & $\mathbf{K}(\mathbf{4})$ \\
\hline 1 & 0.03 & 0.2653 & 0.5817 & 0.0118 & 0.0001 \\
\hline 2 & 0.05 & 0.3139 & 0.6960 & 0.0198 & 0.0003 \\
\hline 3 & 0.07 & 0.3607 & 0.8081 & 0.0279 & 0.0005 \\
\hline
\end{tabular}

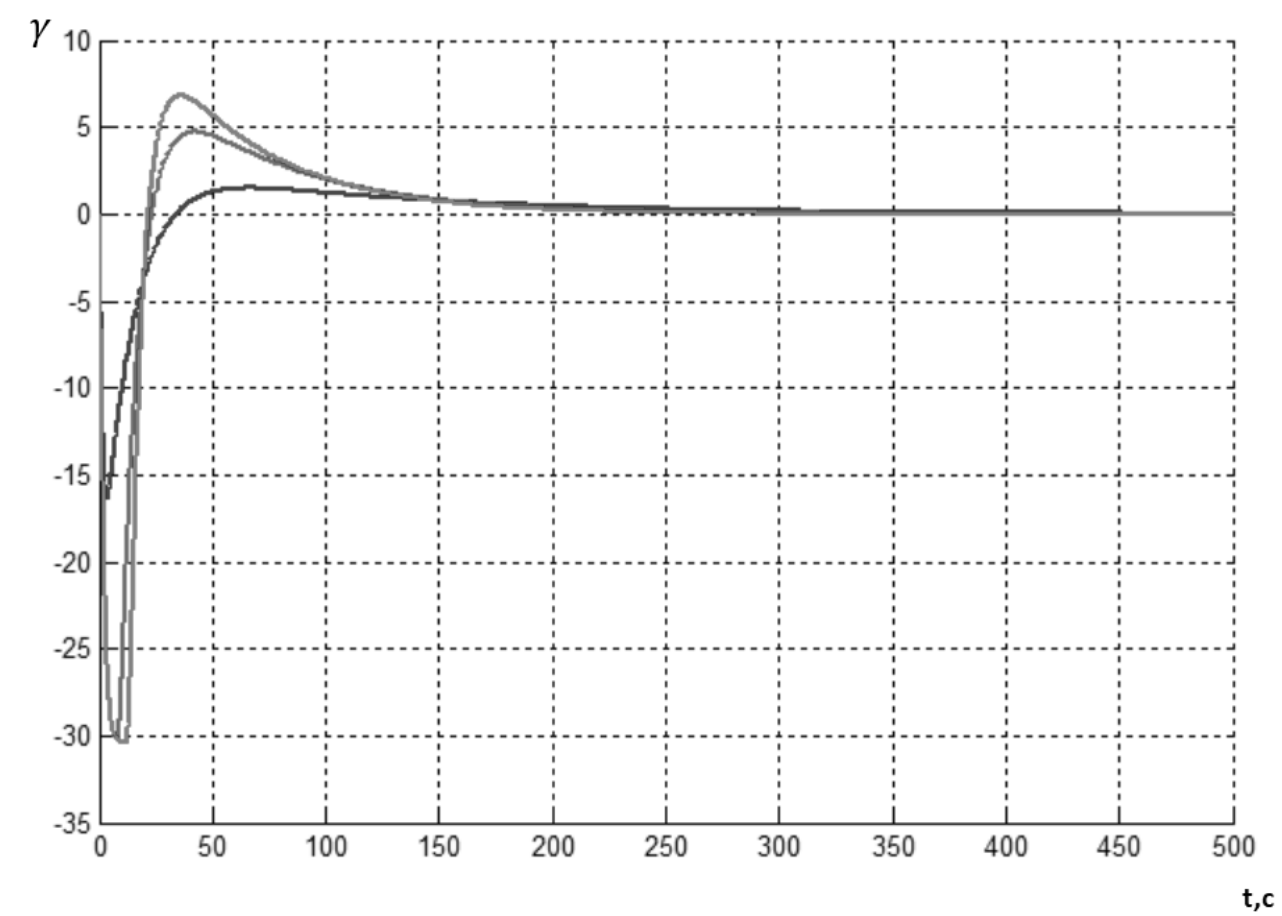

Рис. 7. Переходный процесс по углу крена в полуавтоматической системе управления

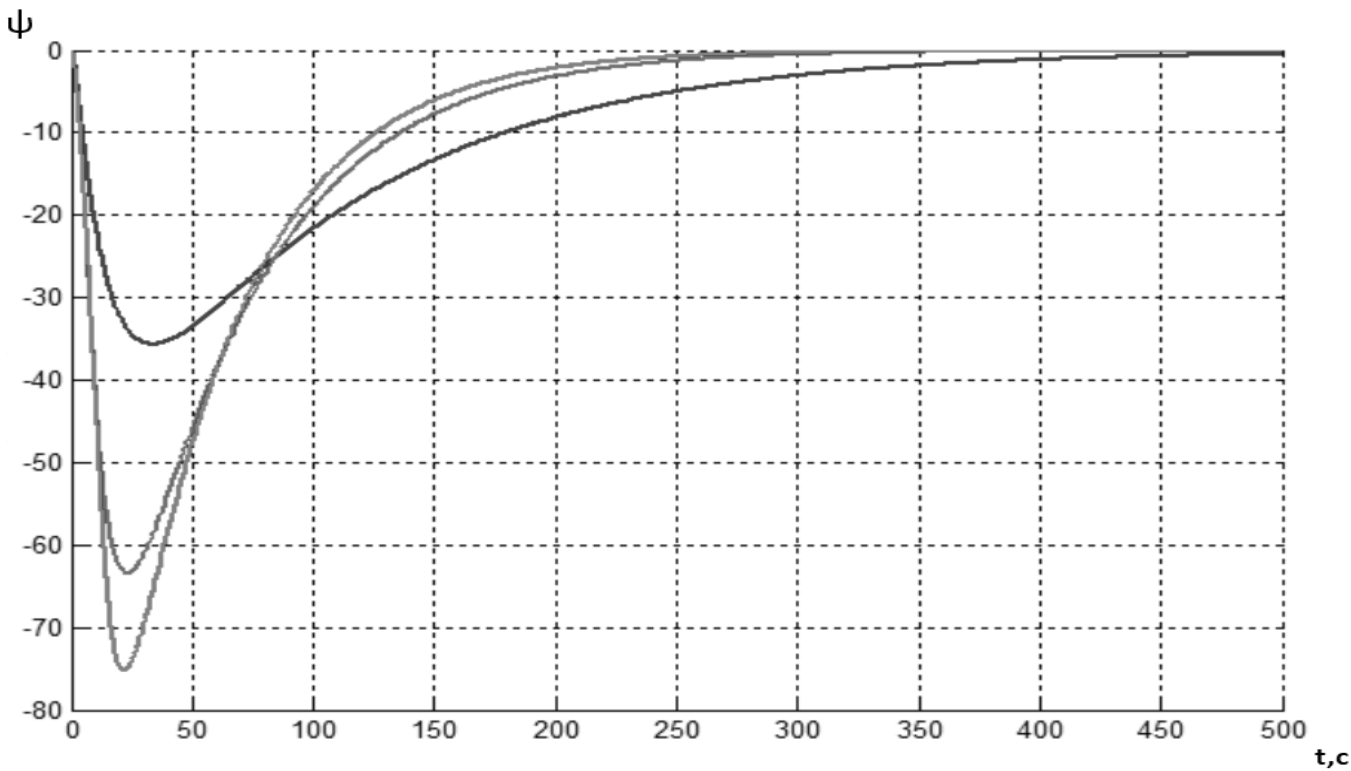

Рис. 8. Переходный процесс по углу курса в полуавтоматической системе управления 


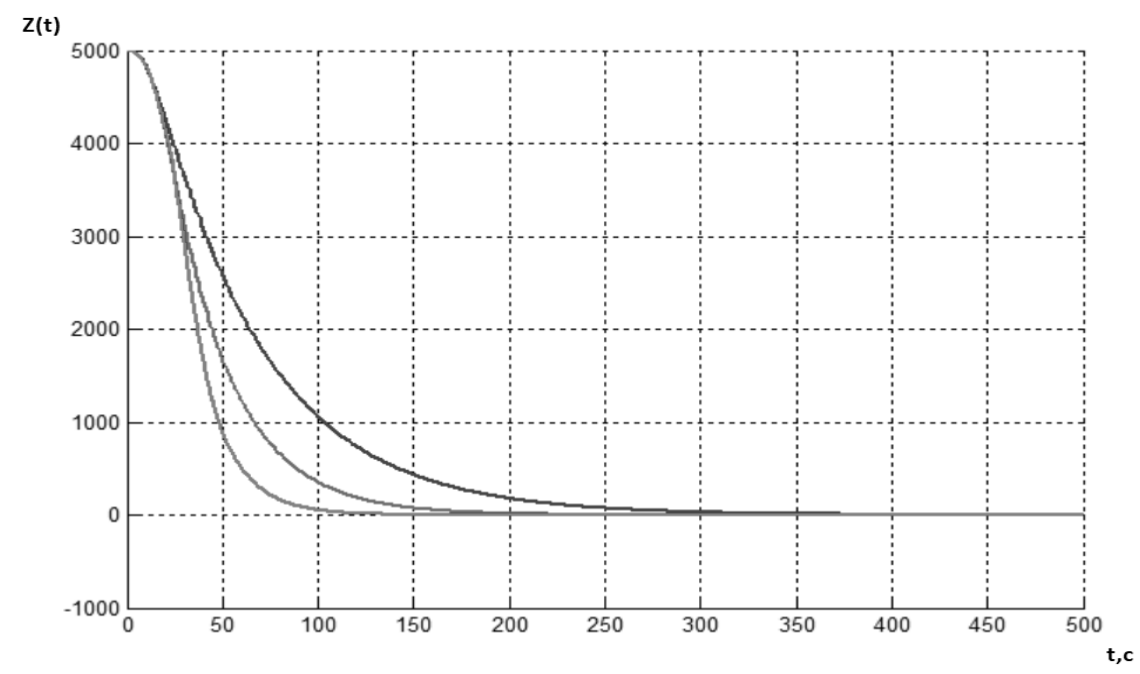

Рис. 9. Линии траектории самолета Z(t) при выполнении S-образного маневра.

В таблице 2 значения коэффициентов закона управления при отработке заданного значения угла крена $\gamma_{\text {зад }}=30^{\circ}$.

Результаты математического моделирования при отработке заданного значения угла крена $\gamma_{\text {зад }}=30^{\circ}$ при ограничении отклонения элеронов $\pm 15^{\circ}$ представлены на рисунках 3 и 4.

Результаты математического моделирования при отработке заданного значения угла крена $\gamma_{\text {зад }}=30^{\circ}$ при ограничении отклонения элеронов $\pm 15^{\circ}$ представлены на рисунках 5 и 6.

Для S-образного маневра при $\mathrm{z}_{0}=5000 \mathrm{M}, \mathrm{\gamma}_{0}=0^{\circ}, \Psi_{0}=0^{\circ}$, $|\gamma|_{\max }=30^{\circ}$ получены значения времени переходного процесса $T_{n n}$, показанные на рисунках 7, 8 и 9, значения коэффициентов параметров системы полуавтоматического управления приведены в таблице 3.

\section{Зак^ючение}

Показан принцип построения полуавтоматической системы управления положением центра масс самолета в боковом движении для имитатора блока комплексной системы управления тренажерного устройства имитации полета перспективного среднемагистрального пассажирского самолета. Математическая модель объекта управ-

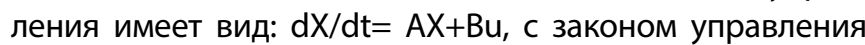
$\mathrm{u}=-\mathrm{KX}$, который минимизирует заданный функционал.

$$
\begin{aligned}
& J=\int_{0}^{\infty} F\left(x_{1}, x_{2}, \ldots, x_{n}, u\right) d t= \\
& =\int_{0}^{\infty}\left[\sum_{i=1}^{n} d_{i} x_{i}^{2}(t)+d_{u} u^{2}(t)\right] d t .
\end{aligned}
$$

Получены коэффициента закона управления и построены качественные переходные процессы.

1. David Allerton, Principles of Flight Simulation, John Wiley \& Sons, Ltd, 2009

2. Красовский, А.А. Авиационные тренажеры / А.А. Красовский [и др.] - М.: Изд. ВВИА им. Жуковского, 1992.— 320 с.

3. Бюшгенс Г.С., Студнев Р.В. Динамика пространственного движения самолета. М.: Машиностроение, 1965.— 370 С., ил.

4. Динамика полета: Учебник для авиационных вузов / Мхитрян А.М., Лазнюк П.С., Максимов В.С. и др.- М.: Машиностроение, 1978. - 424 .

5. Пашковский И.М. Динамика и управляемость самолета.-М.: Машиностроение, 1987. — 429 с.

6. Красовский А.А. Основы теории авиационных тренажеров. М.: Машиностроение, 1995. - 304 с., ил. 